\title{
Isolation, Characterization and Cytotoxic Potential of Desmodium oojeinensis (Roxb) H. Ohashi: A Threatened Medicinal Plant
}

\author{
Sparsha Bandekar ${ }^{1,2}$, Arun B. Joshi ${ }^{2}$, Anant V. Bhandarkar², Shailendra Gurav ${ }^{2}$, Mythili Krishna Jeedigunta $^{2}$ \\ ${ }^{1}$ Department of Pharmacognosy, Yashwantrao Bhonsale College of Pharmacy Sawantwadi. Maharastra, India. \\ ${ }^{2}$ Department of Pharmacognosy, Goa College of Pharmacy, Goa University, Panaji, Goa, India.
}

\begin{tabular}{l}
\hline ARTICLE INFO \\
\hline Received on: $23 / 06 / 2020$ \\
Accepted on: 01/12/2020 \\
Available online: 05/02/2021 \\
\hline Key words: \\
Desmodium oojeinensis, \\
Fabaceae, betulin, betulinic \\
acid,16-hydroxybetulin, \\
lupeol.
\end{tabular}

\begin{abstract}
Desmodium oojeinensis, which belongs to the family Fabaceae, is an endangered plant native to the Himalayan and sub-Himalayan tract. The current work aimed to carry out physicochemical, phytochemical screening, isolation, and in vitro cytotoxic activity using MCF-7 and A-549 cell lines by using the sulforhodamine B method. The physicochemical parameters tested were found to comply with pharmacopoeial limits. The extract's phytochemical screening revealed triterpenoids, alkaloids, anthraquinone glycosides, flavonoids, and carbohydrates. Four phytoconstituents belonging to the class of triterpenoids, viz. betulin, betulinic acid, 16-hydroxybetulin, and lupeol, were isolated from the ethanolic extract by column chromatography. The ethanolic extract showed moderate cytotoxic activity on the human lung cancer cell line A-549 at a concentration of $80 \mu \mathrm{g} / \mathrm{ml}$ and growth inhibition of $81.5 \%$. The extract failed to hinder the growth of the human breast cancer cell line MCF-7.
\end{abstract}

\section{INTRODUCTION}

Medicinal plants have proven to be potent allies since time immemorial by curbing various health ailments. Although synthetic drugs have substituted herbal healing to a certain level, the resurgence and attentiveness of herbal medicines are returning (Acharya and Shrivastava, 2008). Medicinal plants are affordable and ecofriendly, but possess (Tridevi, 2008) fewer side effects than synthetic drugs. Among the modern drugs in use today, about $40 \%$ are of natural origin. Approximately $60 \%$ of anti-cancer remedies and $75 \%$ of drugs for infectious diseases are natural or derivatives (Samuelsson and Bohlin, 2009). Among the numerous plants available in nature, few of them have attracted scientists' interest to investigate cancer treatment. Phytoconstituents have played a crucial role in developing leads, which are proved to be clinically valuable in treating neoplasm (Shah B et al., 2010).

Desmodium oojeinensis (Roxb) H. Ohashi is a medicinal plant that belongs to the family Fabaceae. It is commonly known as sandan, Tinsa in Hindi, and Ratha in Sanskrit. It is a deciduous tree

${ }^{*}$ Corresponding Author

Anant V. Bhandarkar, Department of Pharmacognosy,

Goa College of Pharmacy, Panaji, India.E-mail: anantpharm@gmail.com that is distributed among the Himalayan tracks up to an altitude of 1,500 mts and spread across the whole of northern and central India. Traditionally, it is used for various ailments, such as an astringent, stimulant, anti-inflammatory, urinary astringent, acrid anthelmintic, cooling, and rejuvenating (Kirtikar and Basu, 2006; Nadkarni, 1976). Scientifically, the extract from various parts of the D. oojeinensis plant were screened for anti-inflammatory, analgesic, antispasmodic, hepatoprotective, wound healing, and antimicrobial activities (Khare, 2004; Mandrekar et al., 2014; Sahu and Roy, 2009; Sahu et al., 2008, 2009). Phytoconstituents, namely genistin, kempferol, lupeol, butuline, hydroxylupeol, and isoflavones, like dalvergioidin, homoferreirin, and Eugenie, from various parts of the plant have been reported (Balakrishna et al., 1962; Ghosh and Dutta, 1965; Mukherjee et al., 1963).

The current work aimed to accomplish physicochemical, phytochemical screening, isolation, and in vitro cytotoxic activity using MCF-7 and A-549 cell lines by using the sulforhodamine B (SRB) method.

\section{MATERIALS AND METHODS}

\section{Collection and authentication}

The fresh bark of the stem was collected from fully grown D. oojeinensis (Roxb) H. Ohashi plants from Chitradurga, Karnataka, India. It was authenticated by Dr. K. Gopalkrishna 
Bhat, Department of Botany, Poornaprajna College, Udupi. The archived specimen is banked at Goa College of Pharmacy (GCP/ Ph.cog 2019/P001) for future reference.

\section{Physicochemical parameters}

Various physicochemical parameters, such as swelling index, moisture content, foaming index, ash values, and extractive values, were determined as per the World Health Organization's guidelines (Anonymous, 1998).

\section{Extraction and preparation of extract}

Coarsely powdered $400 \mathrm{~g}$ of air-dried stem bark was extracted with ethyl alcohol $(95 \%)$ for a period of 3 days at room temperature. The ethanolic layer was decanted off. The operation was repeated thrice. By the rotary vacuum evaporator, the solvent was recovered, and the residue was evaporated and concentrated to a syrupy consistency and then dissipated to dryness $(4.25 \% \mathrm{w} / \mathrm{v})$.

\section{Preliminary phytochemical screening}

Preliminary phytochemical studies were carried out on the ethanolic extract of the bark of the stem of $D$. oojeinensis to check for the presence of chemical constituents like alkaloids, carbohydrates, glycosides, flavonoids, triterpenoids, steroids, tannins, phenolic compounds, proteins, resins, starch, etc. (Khandelwal, 2010; Kokate et al., 2006; Shah and Seth, 2010).

\section{ISOLATION OF PHYTOCONSTITUENTS}

$15 \mathrm{~g}$ ethanolic extract was dissolved in ethanol and mixed with $15 \mathrm{~g}$ silica gel (\#60-120) for adsorption. The adsorbed sample was loaded on a column previously packed with $250 \mathrm{~g}$ of silica gel (\#60-120) using Pet. ether. The column was eluted with different solvent systems in increasing order of their polarity, starting with Pet. ether (60-80) $100 \%$, followed by Pet. ether: $\mathrm{CHCl}_{3}$-graded mixtures $(95: 5,90: 10,70: 30,50: 50,30: 70$, and 10:90). This was followed by $\mathrm{CHCl}_{3} 100 \%$ and then $\mathrm{CHCl}_{3}$ : EtOAc graded mixtures, (95:5, 90:10, 70:30, 50:50, 30:70, and 10:90). Finally, the column was eluted with EtOAc and then with, EtOAc :MeOHgraded mixtures $(99: 1,98: 2,95: 5,90: 10,85: 5$, and 80:20). The elutions were collected and observed by TLC (silica gel GF 254, visualization under UV 254 and 366), and then identical elutes were combined, concentrated, and processed further to obtain the chemical constituents. The fraction obtained by elution with chloroform $(100 \%)$ was washed with n-Hexane to afford a white amorphous powder DO $1(45 \mathrm{mg})$. The fraction obtained by elution with $\mathrm{CHCl}_{3}$ :EtOAc (70:30) resulted in a white amorphous powder DO $2(48 \mathrm{mg})$. The fraction eluted with EtOAc (100\%) was recrystallized with $\mathrm{MeOH}$ to obtain buff-colored crystals DO 3 (90 mg). EtOAc :MeOH (95:5) eluent gave white crystals DO 4 (40 mg). The MP, IR, NMR, and mass spectroscopic analysis of the isolated compounds were carried out and the structures were identified with the reported values.

\section{In vitro cytotoxic activity}

In vitro cytotoxic activity of the ethanolic extract of $D$. oojeinensis was executed by SRB assay. The sample was prepared in dimethyl sulfoxide (DMSO) to obtain the concentration of $100 \mu \mathrm{g} / \mathrm{ml}$. Human breast cancer cell lines, MCF-7, and human lung cancer cell line, A-549, were seeded at a density of $10^{3}$ per well in a 96-well Petri plate. The plates were incubated after the addition of samples at concentrations of $10,20,40$, and $80 \mu \mathrm{g} /$ $\mathrm{ml}$ and incubated at $37^{\circ} \mathrm{C}$ for 48 hours in a $5 \% \mathrm{CO}_{2}$ incubator. The assay was ceased by the addition of cold trichloroacetic acid (TCA). $30 \% w / w$ TCA $(50 \mu \mathrm{l})$ was used to root the cells in situ and incubated for 60 minutes at $4^{\circ} \mathrm{C}$. The supernatant was rejected, and the plates were rinsed with tap water, and allowed to air-dry. All the wells were supplemented with $50 \mu \mathrm{l}$ SRB solution $(0.4 \%$ $w / w$ in $1 \%$ acetic acid). The plates were incubated for 20 minutes at $27^{\circ} \mathrm{C} .1 \% \mathrm{w} / \mathrm{w}$ acetic acid was used to remove unbound dye, and the plates were dried. The bound stain was eluted with $10 \mu \mathrm{M}$ Trizma base and absorbance was taken at $540 \mathrm{~nm}$. The values were recorded in triplicate and compared with the standard adriamycin $(10-80 \mu \mathrm{g})$. Growth (\%) was calculated on the plate-by-plate basis for tested wells compared to control wells. Growth (\%) was articulated using the following formula: Average absorbance of test wells $\times 100 /$ Average absorbance of control wells (Houghton et al., 2007; Lamkanfi et al., 2008).

\section{Statistical analysis}

Mean \pm standard deviation (S.D.) was used to express the values.

\section{RESULTS AND DISCUSSION}

The results of physicochemical and phytochemical investigations are depicted in Tables 1 and 2, respectively. The physicochemical investigation of the powdered bark of the stem of $D$. oojeinensis was found to be within the limits of pharmacopoeial standards. A preliminary phytochemical investigation of the ethanolic extract disclosed the existence of alkaloids, carbohydrates, flavonoids, triterpenoids, steroids, tannins, phenolic compounds, and anthraquinone glycosides.

Betulin (DO 1) was isolated as white amorphous powder that was analyzed for the molecular formula $\mathrm{C}_{30} \mathrm{H}_{50} \mathrm{O}_{2}$ by ESIMS $m / z 442.5\left[\mathrm{M}^{+}\right]$. The $\mathrm{mp}$ was $255-256^{\circ} \mathrm{C}$, IR spectrum showed bands $\left(\mathrm{cm}^{-1}\right)$ at 3,387.43 (br, $\left.\mathrm{OH}\right), 2,942.21\left(\mathrm{C}-\mathrm{H}\right.$ str in $\left.\mathrm{CH}_{3}\right)$, 1,453.44 (C-H deformation in germinal dimethyl), 1,033.40 (C-O str in $2^{\circ}$ alcohol). The analysis of ${ }^{1} \mathrm{H}$ NMR (400 MHz, DMSO, $\delta$, ppm): 4.64 (2H, s, H-29b), 4.53 (2H, s, H-29a), 3.75-3.76 (2H, d, $J=5.44 \mathrm{~Hz}, \mathrm{H}-28), 3.07-3.10$ (1H, m, H-3), 2.95-3.00 (1H, m, H-19), 2.37-2.38 (2H, t, $J=5.32 \mathrm{~Hz}, \mathrm{H}-15), 1.84-1.93$ (6H, m, H-16,21,22), 1.63 (3H, s, H-30), 1.45-1.61 (8H, m, H-1,2,6,13,18), 1.23-1.27 (3H, t, $J=5.04 \mathrm{~Hz}, \mathrm{H}-7,9), 1.05-1.17$ (4H, m, H-11 \&12), 0.98 (3H, s, H-26), 0.93 (3H, s, H-27), 0.88 (3H, s, H-23), 0.77 (3H, s, H-25), 0.72 (3H, s, H-24), 0.61-0.66 (1H, t, H-5); $\mathrm{C}^{13}$ NMR (400 MHz, DMSO, $\delta$ ppm): 39.32 (C1), 18.72 (C2), 79.15 (C3), 39.52 (C4), 54.83 (C5), 17.92 (C6), 36.63 (C7), 40.40(C8), 49.81 (C9), 38.26 (C10), 24.73 (C11), 26.60 (C12), 38.44 (C13), 42.14 (C14), 27.99 (C15), 29.29 (C16), 47.34 (C17), 47.30 (C18), 48.14 (C19), 150.17 (C20), 28.95 (C21), 33.78 (C22), 27.09 (C23), 15.62 (C24), 15.83 (C25), 15.64 (C26), 14.43 (C27), 57.97 (C28), 109.43 (C29), 20.32 (C30).

Betulinic acid (DO 2) was isolated as white amorphous powder that was analyzed for the molecular formula $\mathrm{C}_{30} \mathrm{H}_{48} \mathrm{O}_{3}$ by ESIMS $m / z 456.5\left[\mathrm{M}^{+}\right]$. The $\mathrm{mp}$ was $317-318^{\circ} \mathrm{C}$, IR spectrum showed bands $\left(\mathrm{cm}^{-1}\right)$ at 3,399.10 (br, OH), 2,950.70 (C-H str in $\left.\mathrm{CH}_{3}\right), 1,714.21\left(\mathrm{C}=\mathrm{O}\right.$ str in acid), $1,451.40 \mathrm{~cm}^{-1}$ (C-H deformation in germinal dimethyl), $1,023.20 \mathrm{~cm}^{-1}$ (C-O str in $2^{\circ}$ alcohol). The 


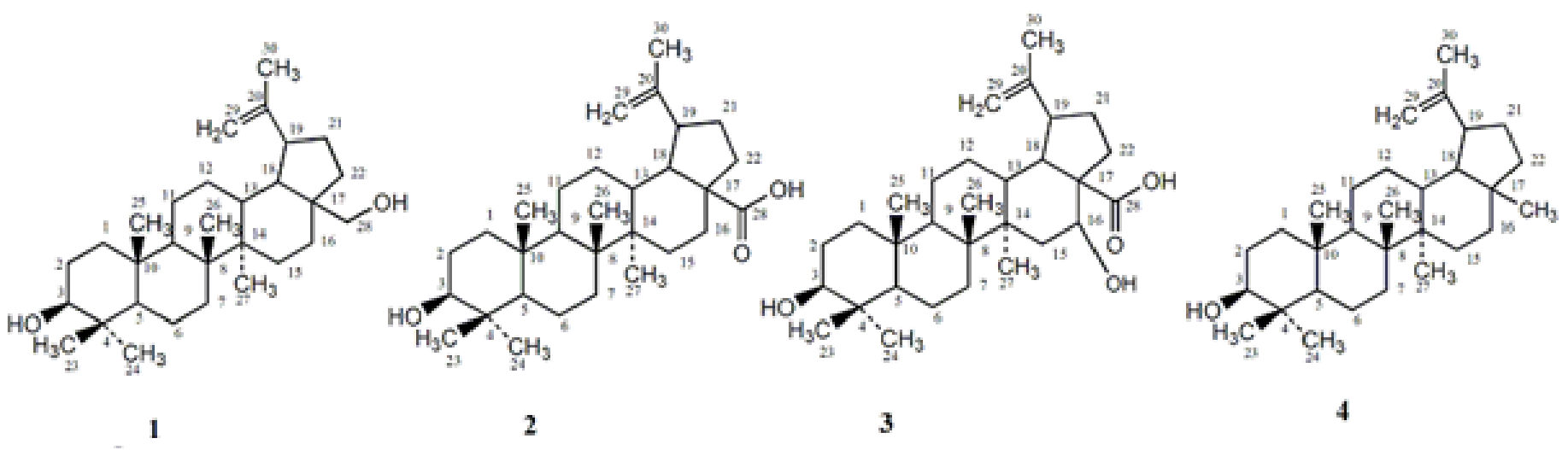

Figure 1. Structures of isolated phytoconstituents: betuline (DO 1) [1], betulinine acid (DO 2) [2], 16-hydroxybetulinic acid (DO 3) [3], and lupeol (DO 4)[4].

analysis of ${ }^{1} \mathrm{H}$ NMR (400 MHz, DMSO, $\left.\delta, \mathrm{ppm}\right): 4.66(2 \mathrm{H}, \mathrm{s}$, H-29b), 4.59 (2H, s, H-29a), 3.50-3.56 (2H, m, H-3,19), 2.37$2.43(3 \mathrm{H}, \mathrm{m}, \mathrm{H}-13,15), 1.75(3 \mathrm{H}, \mathrm{s}, \mathrm{H}-30), 1.48-1.57(7 \mathrm{H}, \mathrm{m}$, H-2,18,21,22), 1.34-1.45 (6H, t, $J=6.92 \mathrm{~Hz}, \mathrm{H}-6,7,16), 1.15-$ 1.26 (5H, m, H-9, 11 \& 12), 1.11 (3H, s, H-23), 1.09 (3H, s, H-26), 1.05 (3H, s, H-27), 1.02 (3H, s, H-24), 0.97 (3H, s, H-25), 0.720.78 (3H, m, H-1,5); $\mathrm{C}^{13} \mathrm{NMR}(400 \mathrm{MHz}, \mathrm{DMSO}, \delta \mathrm{ppm}): 39.04$ (C1), 27.39 (C2), 78.49 (C3), 39.11 (C4), 55.57 (C5), 18.55 (C6), 33.78 (C7), 40.44 (C8), 50.10 (C9), 38.44 (C10), 21.07 (C11), 24.73 (C12), 38.78 (C13), 42.17 (C14), 29.92 (C15), 32.32 (C16), 47.37 (C17), 48.14 (C18), 49.47(C19), 150.15 (C20), 30.28 (C21), 38.26 (C22), 27.95 (C23), 16.32 (C24), 16.51 (C25), 16.77 (C26), 15.75 (C27), 180.87 (C28), 108.48 (C29), 19.12 (C30).

16-Hydroxybetulinic acid (DO 3) was isolated as buffcolored crystals that were analyzed for the molecular formula $\mathrm{C}_{30} \mathrm{H}_{48} \mathrm{O}_{4}$ by ESIMS $\mathrm{m} / z 472.5\left[\mathrm{M}^{+}\right]$. The mp was $271-273^{\circ} \mathrm{C}$, IR spectrum showed bands $\left(\mathrm{cm}^{-1}\right)$ at 3,351.40 (br, OH), 2,952.47 $\left(\mathrm{C}-\mathrm{H}\right.$ str in $\left.\mathrm{CH}_{3}\right), 1,712.71\left(\mathrm{C}=\mathrm{O}\right.$ str in acid), $1,451.41 \mathrm{~cm}^{-1}(\mathrm{C}-\mathrm{H}$ deformation in germinal dimethyl), $1,026.20 \mathrm{~cm}^{-1}$ (C-O str in $2^{\circ}$ alcohol). The analysis of ${ }^{1} \mathrm{H}$ NMR (400 MHz, DMSO, $\left.\delta, \mathrm{ppm}\right)$ : 4.71 (2H,s, H-29b), 4.60 (2H, s, H-29a), 4.18-4.22 (1H, dd, $J=$ 5.2, 6.36 Hz, H-16), 3.49-3.55 (2H, m, H-3, 19), 2.35-2.45 (1H, m, H-13), 1.811-1.83 (2H, d, $J=7.32 \mathrm{~Hz}, \mathrm{H}-15), 1.77$ (3H, s, H-30), 1.51-1.61 (7H, m, H-2,18,21,22), 1.36-1.49 (6H, m, H-1,6,7), 1.15-1.26 (5H, m, H-9,11 \&12), $1.11(3 \mathrm{H}, \mathrm{s}, \mathrm{H}-23), 1.08(3 \mathrm{H}, \mathrm{s}$, H-26), 1.04 (3H, s, H-27), 1.00 (3H, s, H-24), 0.87 (3H, s, H-25), $0.74-0.76(1 \mathrm{H}, \mathrm{t}, J=9.24 \mathrm{~Hz}, \mathrm{H}-5)$; $\mathrm{C}^{13} \mathrm{NMR}(400 \mathrm{MHz}, \mathrm{DMSO}$, $\delta$ ppm): 39.07 (C1), 27.39 (C2), 78.55 (C3), 39.15 (C4), 55.43 (C5), 18.54 (C6), 34.26 (C7), 40.45 (C8), 50.11 (C9), 37.38 (C10), 21.10 (C11), 24.73 (C12), 38.26 (C13), 42.17 (C14), 29.90 (C15), 79.67 (C16), 49.17, (C17), 49.54 (C18), 49.73 (C19), 150.55 (C20), 30.27 (C21), 37.00 (C22), 27.96 (C23), 16.31 (C24), 16.51 (C25), 16.75 (C26), 15.72 (C27), 180.57 (C28), 109.08 (C29), 19.10 (C30).

Lupeol (DO 4) was isolated as white crystals that were analyzed for the molecular formula $\mathrm{C}_{30} \mathrm{H}_{50} \mathrm{O}$ by ESIMS $\mathrm{m} / \mathrm{z} 426.4$ $\left[\mathrm{M}^{+}\right]$. The mp was $210-212^{\circ} \mathrm{C}$, IR spectrum showed bands $\left(\mathrm{cm}^{-1}\right)$ at 3,374.46 (br, OH), 2,934.35 $\left(\mathrm{C}-\mathrm{H}\right.$ str in $\left.\mathrm{CH}_{3}\right), 1,635.57(\mathrm{C}=\mathrm{C}$ str), 1,463.74 $\mathrm{cm}^{-1}$ (C-H deformation in germinal dimethyl), $1,034.49 \mathrm{~cm}^{-1}$ (C-O str in $2^{\circ}$ alcohol). The analysis of ${ }^{1} \mathrm{H}$ NMR

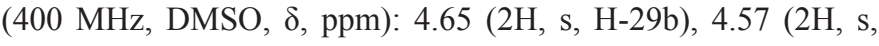

H-29a), 3.07-3.10 (1H, m, H-3), 2.95-3.00 (1H, m, H-19), $2.35-$ $2.38(2 \mathrm{H}, \mathrm{t}, J=4.08 \mathrm{~Hz}, \mathrm{H}-15), 1.83-1.91(2 \mathrm{H}, \mathrm{m}, \mathrm{H}-21), 1.67$ (3H, s, H-30), 1.50-1.62 (8H, m, H-1,2,6,13,18), 1.23-1.37 (7H, m, H-7,9,16,22), 1.06-1.17 (4H, m, H-11,12), 1.02 (3H, s, H-27), 0.95 (3H, s, H-26), 0.92 (3H, s, H-25), 0.81 (3H, s, H-24), 0.77 $(3 \mathrm{H}, \mathrm{s}, \mathrm{H}-23), 0.75$ (3H, s, H-28), 0.61-0.62 (1H, t, $J=3.52 \mathrm{~Hz}$, $\mathrm{H}-5)$; $\mathrm{C}^{13} \mathrm{NMR}$ (400 MHz, DMSO, $\delta$ ppm): $38.01 \quad$ (C1), 27.47 (C2), 79.09 (C3), 38.78 (C4), 55.30 (C5), 18.33 (C6), 33.78 (C7), 40.16 (C8), 50.40 (C9), 37.71 (C10), 21.07 (C11), 25.13 (C12), 37.92 (C13), 42.84 (C14), 27.39 (C15), 35.58 (C16), 48.25 (C17), 48.14 (C18), 48.03 (C19), 150.00 (C20), 28.52 (C21), 40.00 (C22), 28.11 (C23), 15.32 (C24), 16.30 (C25), 15.85 (C26), 14.52 (C27), 18.01 (C28), 109.04 (C29), 19.47 (C30).

\section{In-vitro cytotoxic study}

The cytotoxic study results on human lung cancer cell lines, A-549, and human breast cancer cell lines, MCF-7, are given in Tables 3 and 4 . The result indicates moderate cytotoxic activity against A-549 cell lines at $80 \mu \mathrm{g} / \mathrm{ml}$ with growth inhibition of $81.5 \%$ when compared to the standard adriamycin with percentage growth inhibition of $<10 \mu \mathrm{g} / \mathrm{ml}$. The extract failed to show in vitro cytotoxic activity against MCF-7 cell lines. The majority of pentacyclic triterpenoids have proved to possess cytotoxic activity. Betulin and betulinic acid exhibit effective anti-cancer activity by activating the mitochondrial apoptosis pathway in tumor cells (Hordyjewska et al., 2018). Chemical investigation led to the isolation of terpenoids having lupine moiety, isolated from the extract of $D$. oojeinensis, which may be responsible for moderate cytotoxic activity against human lung cancer cell lines A-549.

\section{CONCLUSION}

The current research work on the bark of the stem of D. oojeinensis was successfully explored. The physicochemical parameters tested were found to be within the pharmacopoeial limits. Chemical examination of the extract was directed to the separation of four triterpenoids, namely betulin, betulinic acid, 16-hydroxybetulinic acid, and lupeol. Based on a literature survey, betulin and betulinic acid exhibited significant cytotoxic activity. The ethanolic extract showed moderate cytotoxic activity in A-549. The activity might be endorsed due to betulin and betulinic acid, which have been isolated from D. oojeinensis. Apoptosis 
and in vivo studies will further potentiate its claim as an effective cytotoxic agent in lung cancer treatment.

\section{ACKNOWLEDGMENTS}

The authors are thankful to Dr. K. Gopalkrishna Bhat, Department of Botany, Poornaprajna College, Udupi, for authenticating the plant material. The authors are also thankful to the authorities of the Government of Goa and Principal, GCP, Panaji Goa, for providing necessary laboratory facilities. The Sophisticated Analytical Instrumentation Facility Center and Central Instrumentation Laboratory, Punjab University, are highly acknowledged for providing spectral data. The authors also thank the Advanced Centre for Treatment, Research, and Education in Cancer (ACTREC), Mumbai, for carrying out cytotoxic studies.

\section{AUTHOR CONTRIBUTIONS}

All authors made substantial contributions to conception and design, acquisition of data, or analysis and interpretation of data; took part in drafting the article or revising it critically for important intellectual content; agreed to submit to the current journal; gave final approval of the version to be published; and agree to be accountable for all aspects of the work.

\section{FUNDING}

There is no funding to report.

\section{CONFLICTS OF INTEREST}

The authors report no conflicts of interest in this work.

\section{ETHICAL APPROVALS} subjects.

This study does not involve the use of animals or human

\section{REFERENCES}

Acharya D, Shrivastava A. 2008. Indigenous herbal medicines. Aavishkar Publisher, Jaipur, India.

Anonymous. Quality control methods for medicinal plant materials. WHO Library Cataloging in Publication Data, England, UK, 1998.

Balakrishna S, Ramanathan JD, Seshadri TR, Venkataramani B. Special chemical components of the heartwood of Ougeinia dalbergioides Benth. Proc R Soc London Ser A Math Phys Sci, 1962; 268(1332):001-20.

Ghosh AC, Dutta NL. Chemical investigation of Ougeinia dalbergioides Benth. J Indian Chem Soc, 1965; 42(12):831-5.

Hordyjewska A, Ostapiuk A, Horecka A. Betulin and Betulinic acid in cancer research. J Pre-Clin Clin Res, 2018; 12(2):72-5.
Houghton P, Fang R, Techatanawat I, Steventon G, Hylands P, Lee CC. The sulphorhodamine (SRB) assay and other approaches to testing plant extracts and derived compounds for activities related to reputed anticancer activity. Methods, 2007; 42(4):377-87.

Khandelwal KR. 2010. Practical of pharmcognosy techniques and experiments. Nirali Prakashan, Pune, India.

Khare CP. Indian herbal remedies rational western therapy, ayurvedic and traditional usage, botany. Springer Publications, Berlin, Germany, 2004

Kirtikar KR, Basu BD. 2006. Indian medicinal plant. International Book Distributor, Dehradun, India.

Kokate CK, Purohit AP, Gokhale SB. 2012. Textbook of pharmacognosy. Nirali Prakashan, Pune, India.

Lamkanfi M, Kanneganti TD, Damme PV, Berghe TV, Vanoverberghe I, Vandekerckhove J. Targeted peptide centric proteomics reveals caspase- 7 as a substrate of the caspase- 1 inflammasomes. Mol Cell Proteomics, 2008; 7(12):2350-63.

Mandrekar M, Hedgedesai V, Joshi M, Sardessai Y, Joshi A. Antimicrobial activity of ethanolic extract of stem bark of Ougeinia oojeinensis (Roxb.) Hochr. World J Pharm Res, 2014; 3(5):613-22.

Mukherjee DK, Barua AK, Bose PK. Chemical investigation of Ougeinia dalbergioides Benth. Sci Cult, 1963; 29:151-2.

Nadkarni KM. 1976. Indian materia medica. Mumbai, India: Popular Prakashan Pvt. Ltd.

Sahu RK, Roy A. Hepatoprotective activity of ethanolic extract of Ougeinia oojeinensis (Roxb) Hochr in $\mathrm{CCL}_{4}$ treated male rats. Pharmacologyonline, 2009; 2:1-5.

Sahu RK, Dewangan D, Roy A, Namdeo KP. Anti-inflammatory action of Ougeinia oojeinensis (Roxb) Hochr. bark by HRBC membrane stabilization. Res J Pharm Technol, 2008; 1(01):57-8.

Sahu RK, Kulshrestha V, Yadav KS, Roy A. Healing potential of gel containing extract of Ougeinia oojeinensis on excision of wounds in wistar rats. J Glob, 2009; 2:103-6.

Samuelsson G, Bohlin L. Drugs of national origin a treatise of pharmacognosy. Swedish Pharmaceutical Pres, Stockholm, Sweden, 2009.

Shah B, Seth AK. Textbook of pharmacognosy and phytochemistry. Elsevier India Pvt. Ltd, New Delhi, India, 2010.

Tridevi PC. 2008. Medicinal plants: traditional knowledge. I K International Pvt. Ltd, New Delhi, India.

How to cite this article:

Bandekar S, Joshi AB, Bhandarkar AV, Gurav S, Jeedigunta MK. Isolation, characterization, and cytotoxic potential of Desmodium oojeinensis (Roxb) H. Ohashi: A threatened medicinal plant. J Appl Pharm Sci, 2021; 11(02):102-105. 